\title{
Concentration of Solar Energy Using Optical Systems Designed from a Set of Conical Rings
}

\author{
Jorge González-García, Sergio Vázquez-Montiel, \\ Agustin Santiago-Alvarado and Graciela Castro-González \\ Technological University of the Mixteca (UTM) and the National Institute of \\ Astrophysics, Optics and Electronics( INAOE) \\ México
}

\section{Introduction}

Different types of optic systems have been designed, manufactured, and used to concentrate energy, be it solar or otherwise. To mention just a few, we have for example, 1) the design and manufacture of a non-imaging Fresnel lens prototype for use in a solar collector of medium concentration (Leutz et al., 2000). This collector was evaluated in terms of the optical concentration ratio of its lens and the flux distribution on the absorber; 2) the design and manufacture of a low-frequency Fresnel mirror for a fluorescence detector (DiazAnzures et al., 2004), in which the Fresnel mirror was formed from a set of concentric spherical rings; 3 ) the design of mirrors from a set of spherical rings to generate an angular zone of energy concentration one order of magnitude smaller in comparison to the spot size generated with a spherical mirror (González-García et al., 2009), and 4) the optical design of a highly radiative solar flux furnace for Mexico (Riveros-Rosas et al., 2010) which consisted of an arrangement of 409 first surface spherical facets with a hexagonal shape. The configuration of this design was chosen because of its maximum peak concentration and also for economical reasons.

In the case of concentrator systems which involve polished elements such as lenses and/or mirrors, polishing techniques and optical tests are required for their manufacture. In order to reduce time and costs in the manufacture of solid mirrors designed by the concept of concentric spherical rings (a design method proposed more as an alternative in the design of energy concentrating lens and mirrors (González-García et al., 2009)), a classical polishing method was proposed using petal tools designed with Genetic Algorithms (GonzálezGarcía, et al., 2006) and with linear programming, (Santiago-Alvarado, et al., 2007). These lenses or mirrors can also be polished using different-shaped oscillating tools (Leal-Cabrera, et al., 2009). One alternative for testing the quality of polished surfaces is the application of the Ronchi Test (Cornejo-Rodríguez, 2007), which is an inexpensive test and easy to apply. Based on the ronchigram of the surface being tested, and applying Malacara's formula, cubic splines, and Genetic Algorithms, surface errors can be quantified (Cordero-Dávila \& González-García, 2010; Cordero-Dávila, et al., 2011). 
According to the analysis of the influence of the amount of circumsolar radiation in function of the acceptance angle of the absorber (Buie \& Monger, 2004), the results showed that as the CSR of the sunshape increases, the size of the absorber must also increase to accommodate a similar amount of energy, that is, the size of the image increases. For this reason, a previous study proposed the design and manufacture of a mirror that would generate a desired angular size of the concentration of energy (González-García, et al., 2009). One hundred spherical rings, whose optimum curvature radius values were calculated with Genetic Algorithms (GA), were employed in the modeling process of the mirror (see Fig. 1). Using the Full With at Half Maximum criterion (FWHM), the size of the sun-image obtained with this mirror was $16.82 \mathrm{~mm}$, as shown in Fig. 2.

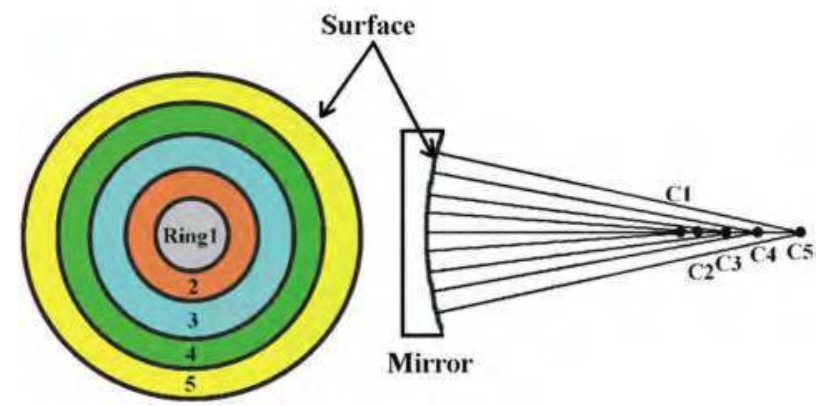

Fig. 1. Mirror modelled from a set of concentric spherical rings.
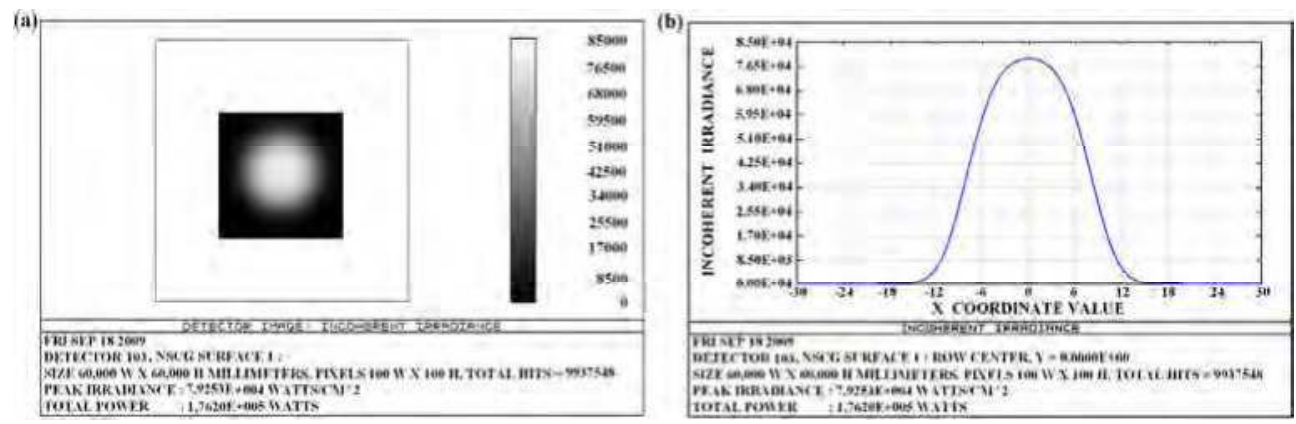

Fig. 2. Sun image generated with the mirror designed from a set of concentric spherical rings: (a) spot diagram and (b) graph of irradiance distribution.

The content of this chapter focuses on the description of a method for designing mirrors that would generate a desired angular size of a point source placed at infinity. Based on the simulation of the mirror by means of the ZEMAX optic design program (ZEMAX, Software For Optical System Design, 2008), the simulated mirror would later generate the corresponding image of the sun. The method for designing mirrors will be based on the above mentioned study of the design of mirrors from a set of concentric spherical rings. In order to be able to generalize the method not only spherical surface rings but also rings with any type of conic surface will be taken into account, that is, rings with any conic surface. One implication of this is that the angular size of the image (found during the optimization 
stage using GA) will now be in function of the conic constant, be it through a predetermined value, or by considering it as a variable to be optimized together with the paraxial curvature radius of each ring. The sun images generated by four mirrors designed from rings whose surfaces have a determined value of the conic constant for each design will be simulated.

\section{Design and optimization}

In line with the procedure for designing a mirror from set of concentric spherical rings which reduce by one order of magnitude the size of an image of a point source placed at infinity, this section presents the design of four mirrors from concentric rings with conic profile whose conic constant for each case are: zero, (original design (González-García, et al., 2009) taken as a comparison), -1 (parabolic rings), -0.5 (rings with elliptical profile), and -1.6279 , whose value was calculated with the GA together with the corresponding curvature radii.

\subsection{Design of energy concentrating mirrors}

Just like the original design (González-García, et al., 2009), these designs of the mirrors are also intended to reduce, by one order of magnitude the angular size of the image generated by a spherical mirror whose parameters are $1,500 \mathrm{~mm}$ in diameter, a curvature radius of $4,000 \mathrm{~mm}$, and a focal distance of 2,000 mm. generating a disc of least confusion of 0.20966 degrees at a distance of $-1,973.0 \mathrm{~mm}$

The design procedure, considering the GA optimization method is expressed through the following steps:

1. 100 rings are used to model the shape of the mirror surface (from a reference sphere with a curvature radius of $3,900 \mathrm{~mm}$, considered for the manufacture stage, by means of petal tool polishing (González-García, et al., 2006)). This involves calculating 100 curvature radii that are the variables to be considered in the optimization.

2. In order to reduce the number of variables to be optimized a recurrence formula was employed to reduce the number of variables from 100 to 20, expressed as

$$
r_{i+1}=r_{i}+\Delta r_{j}
$$

where $r_{\mathrm{i}}(i=1, \ldots, 100)$ are the curvature radii of each one of the rings and $\Delta r_{\mathrm{j}}(j=1, \ldots, 20)$ are the increments of the curvature radii, which would be the variables to be optimized by the GA. These increments are defined by the following equation

$$
\Delta r_{j}=\left[\begin{array}{cll}
m_{1} & \text { if } & 1 \leq i \leq 5 \\
m_{2} & \text { if } & 6 \leq i \leq 10 \\
& \vdots & \\
m_{20} & \text { if } & 96 \leq i \leq 100
\end{array}\right]
$$

3. The fitness function is established as the error square of the differences between the simulated angular size (sas) and the desired angular size (das)

$$
\text { Fitness Fuction }=S^{2}=(\text { sas }- \text { das })^{2}
$$


4. For the first three mirror designs the conic constant of the rings are considered constant whereas for the last design the conic constant is considered as just one more variable to be calculated by the GA, thereby establishing a more general method of design.

Once the design process of the energy concentrating mirrors has been established, the next process is the optimization of the twenty increments of the curvature radii defined by equations 1 and 2. The following is a description of the GA applied to optimize the design of the mirrors.

\subsection{Genetic algorithm applied}

The optimization method applied to calculate the optimum designs of the mirrors is a GA programmed in FORTRAN for LINUX. It has been used in classical surface polishing (González-García, et al., 2006), in the field of optical testing using Ronchi tests (CorderoDávila, et al., 2011), and in optical design (González-García, et al., 2009). The content of this chapter is one more example of this latter application. The stages of the GA applied are briefly described as follows:

\section{A. Generation of the initial population}

In this stage an initial random population of 240 individuals was created for each one of the twenty increments of the curvature radii. Hence, the total number of individuals or values randomly generated in this stage is the product 240X20. Within the area of programming 240 chromosomes were programmed, each one with a longitude of 320 genes. Each one of these chromosomes is divided into 20 chromosomes more (of 16 genes), and each one is used to calculate the value corresponding to each one of the increments of the curvature radii. Fig. 3 shows part of the programming corresponding to this stage.

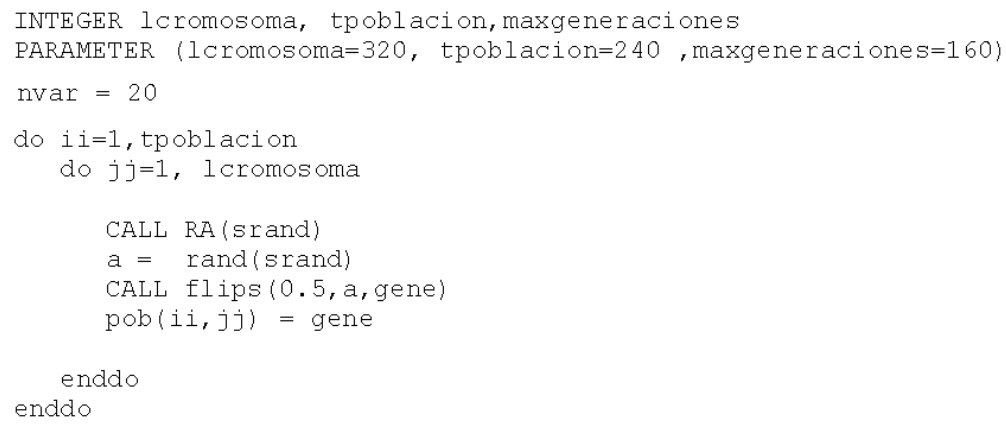

Fig. 3. Programming implemented for the generation of the initial population.

\section{B. Evaluation stage}

Once the initial population has been created, the evaluation stage is performed to determine, by means of the fitness function, Eq. (3), which chromosomes (of 16 genes) are the best values assigned to the increments of the curvature radii, with which Eq. (3) generates a minimum value. This stage was programmed as a subroutine within which the subroutine of ray tracing is found, and with which the simulated angular size is calculated. 


\section{The selection stage}

The next stage in the GA is the selection stage in which the best values of the curvature radii increments are selected by means of the corresponding chromosomes graded as such in the evaluation stage. The selection process employed the tournament technique (GonzálezGarcía, et al., 2009), which consists of randomly taking a certain number of individuals from the population, called tournament size; from this, one of the individuals of the set is chosen for the next generation. The process is repeated as many times as there are individuals in the population, in the present case 240 times. Fig. 4(a) shows the subroutine corresponding to this stage.

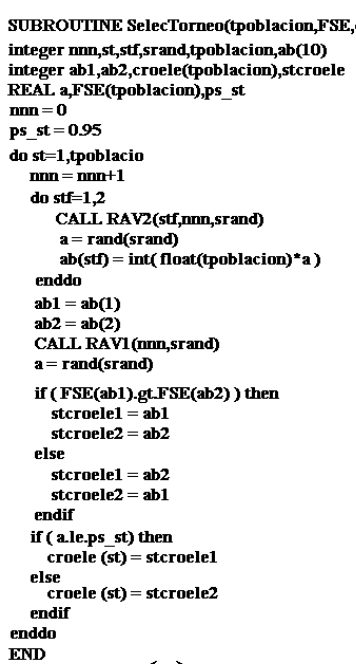

(a)
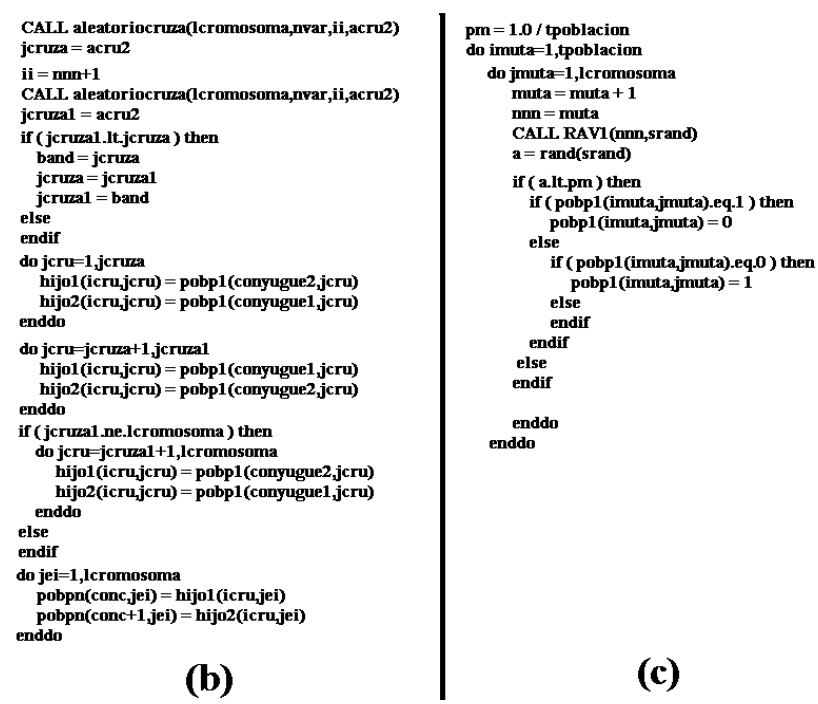

Fig. 4. Parts of the program implemented for Genetic Algorithm in FORTRAN corresponding to the stages of (a) selection, b) crossing, and c) mutation.

\section{Crossing stage}

The next stage to be applied is the crossing stage which involves combining two values of each increment of the curvature radius selected from the previous stage with a view to creating better values of these increments, in other words, values which would make the fitness function generate values close to zero. The crossing technique defined was implemented at two points. Fig. 4(b) shows part of the programming of this implementation.

\section{E. Mutation stage}

The mutation technique implemented was one in which all the genes of each chromosome of the population have the same probability of being mutated. The mutation probability value 
was the inverse of the size of the population. Fig. 4(c) shows the programming corresponding to this stage.

Once the mutation stage has been completed, the evaluation stage is applied once more to determine which members are the best solutions. The whole process is repeated all over again (application of the selection, crossover and mutation stages) to generate populations with better solutions. Each repetition of the process is known as a generation, and as generations come and go, the solutions generated get closer and closer to the optimum solution to the problem. In our application, a population of 240 members was used from a search throughout 160 generations, see Fig. 3.

\subsection{Results obtained from optimization}

The results obtained from GA correspond to the design of 4 mirrors to reduce by one order of magnitude the angular size of the spherical mirror considering as object a point source located at infinity. As previously mentioned, in each design the concentric rings which model the surface of the mirror now have a conic surface profile.

Fig. 5 shows the evaluation graphs of the GA by means of the fitness function against the number of generations corresponding to each one of mirrors designed with different conic constants. Table 1 shows the energy distribution data generated by each mirror.

\begin{tabular}{|c|c|c|c|c|}
\hline Parameter & $\begin{array}{c}\text { Type of } \\
\text { conical ring } \\
\text { used: } \\
\text { Spherical }\end{array}$ & $\begin{array}{c}\text { Type of conical } \\
\text { ring used: } \\
\text { Parabolic }\end{array}$ & $\begin{array}{c}\text { Type of } \\
\text { conical ring } \\
\text { used: } \\
\text { Elliptical }\end{array}$ & $\begin{array}{c}\text { Type of conical } \\
\text { ring used: } \\
\text { Optimized } \\
\text { conic constant }\end{array}$ \\
\hline Conic constant & 0 & -1 & -0.5 & -1.6279 \\
\hline Image position $(\mathrm{mm})$ & -1973 & -1973 & -1973 & -1973 \\
\hline Total spot size $(\mathrm{mm})$ & 0.8405 & 0.7399 & 0.7456 & 0.8449 \\
\hline $\begin{array}{c}\text { Geometrical spot size } \\
(\mathrm{mm})\end{array}$ & 0.2370 & 0.1996 & 0.1907 & 0.2105 \\
\hline $\begin{array}{c}\text { Geometrical rms X/Y } \\
\text { spot size }(\mathrm{mm})\end{array}$ & 0.1676 & 0.1411 & 0.1349 & 0.1488 \\
\hline Angular spot size $\left(^{\circ}\right)$ & 0.0244 & 0.0215 & 0.0217 & 0.0240 \\
\hline
\end{tabular}

Table 1. Data of energy distribution of the four designed mirrors.

Fig. 6 shows the energy distribution generated by each mirror, while Fig. 7 shows the corresponding values of the optimal curvature radii found with GA by means of increments of the curvature radii.

Based on the results obtained from the optimization of the designed mirrors, one can conclude that it is possible to design mirrors which concentrate energy in a smaller area reducing the angular size of the concentration, based on the concept of concentric rings which have a conic type surface, establishing in the design process a conic constant with a specific value or considering it as one more variable to be calculated with the GA. 

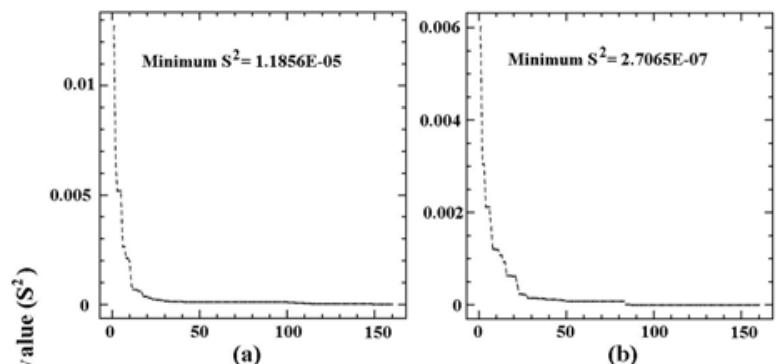

(b)

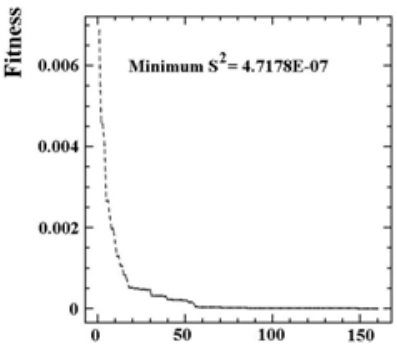

(c)

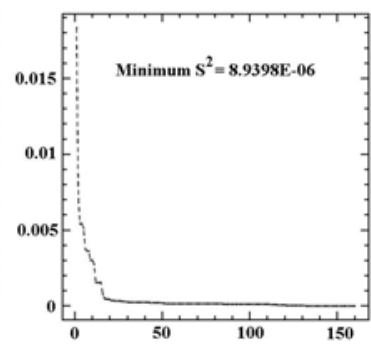

(d)

Generation number

Fig. 5. Graphs of the fitness function as a function of the number of generations produced by the GA for the design of mirrors by means of concentric rings with conic constants of a) 0 , b) -1, c) -0.5 , and d) -1.6279

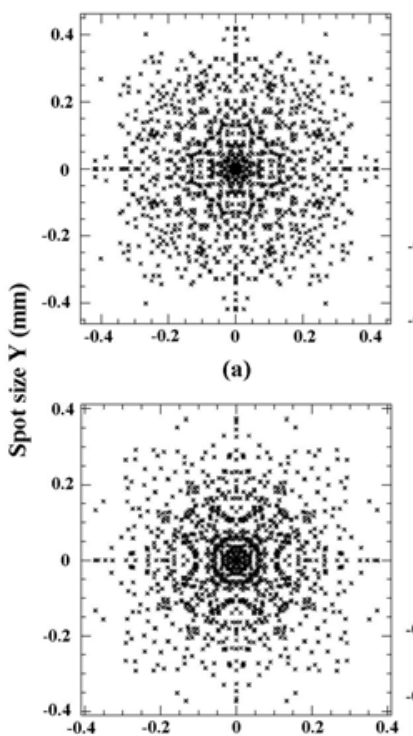

(c)

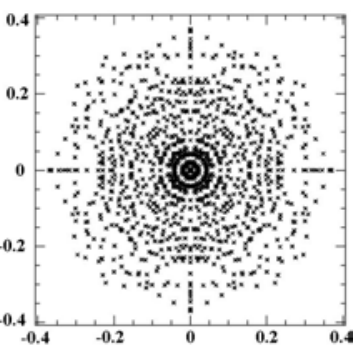

(b)

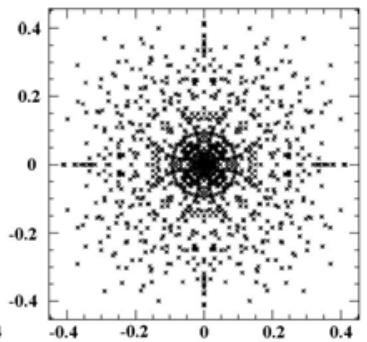

(d)

Spot size X (mm)

Fig. 6. Distribution of energy generated by the mirrors designed with conic constants of a) 0 , b) -1, c) -0.5 and d) -1.6279 . 


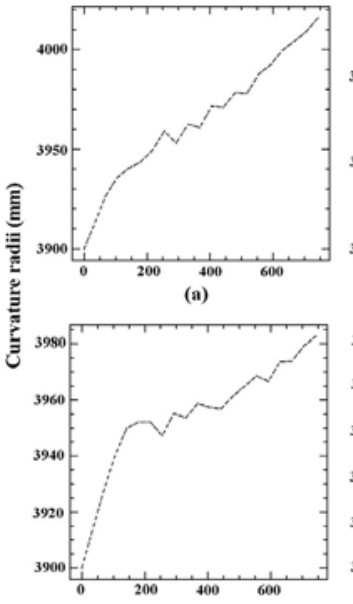

(c)

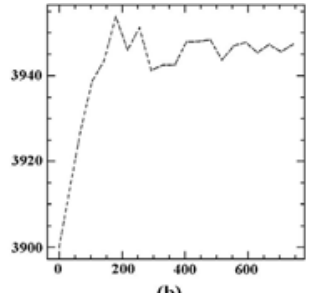

(b)

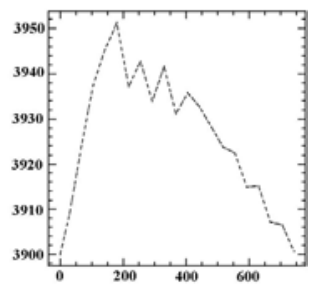

(d)

Fig. 7. Graphs of the optimized curvature radii of the concentric rings which model the 4 mirrors designed with conic constants of a) 0, b) -1, c) - 0.5 and d) -1.6279 .

\section{Simulations done with ZEMAX. Images generated from the sun source}

To consider the sun as an object in the mirrors designed in the previous section, these designs were simulated using the commercial optical design program in version EE of ZEMAX. In order to verify the results obtained of the angular size from each mirror in the optimization stage, see Table 1, the simulations were first done considering as object a point source placed at infinity. Afterwards, the point source was replaced by the sun source in order to generate the corresponding images.

\subsection{Simulations done using a point source}

To do the simulations of the designed mirrors from the concentric rings, the Non-Sequential Mode option was selected in the ZEMAX program. This mode is primarily used for nonimaging applications and its main analysis feature is the ray-trace detector which gives spatial and angular data on incoherent or coherent rays. Fig. 8 shows the statement of the point source, while Fig. 9 shows the statement of some of the curvature radii of the concentric rings through their corresponding aperture and conic constant data. Fig. 10 shows the diagram of rays in the mirror, while Fig. 11 shows the mirror as seen from the front.

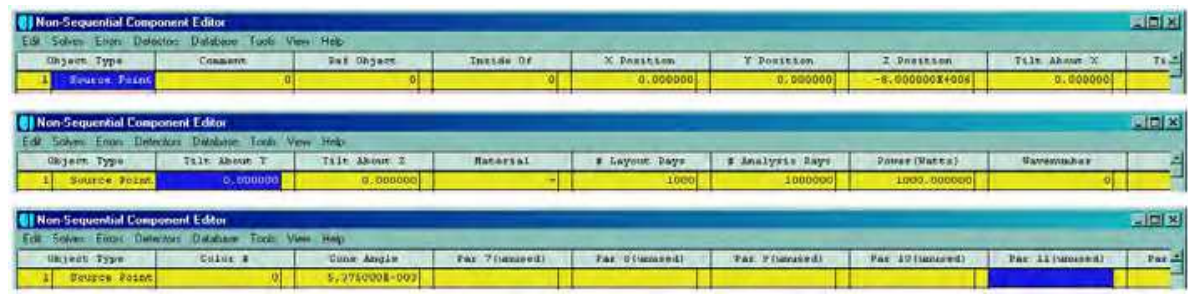

Fig. 8. Statement of the point source in ZEMAX used in the simulation of the designed mirrors. 
Concentration of Solar Energy Using Optical

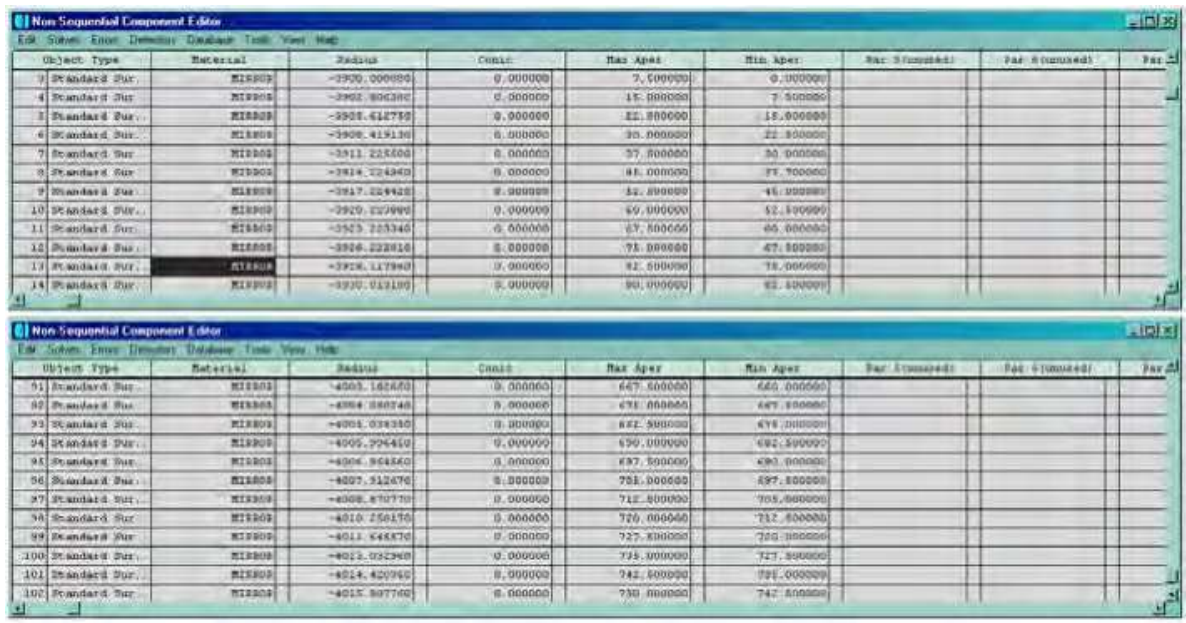

Fig. 9. Statement of the concentric rings in ZEMAX.

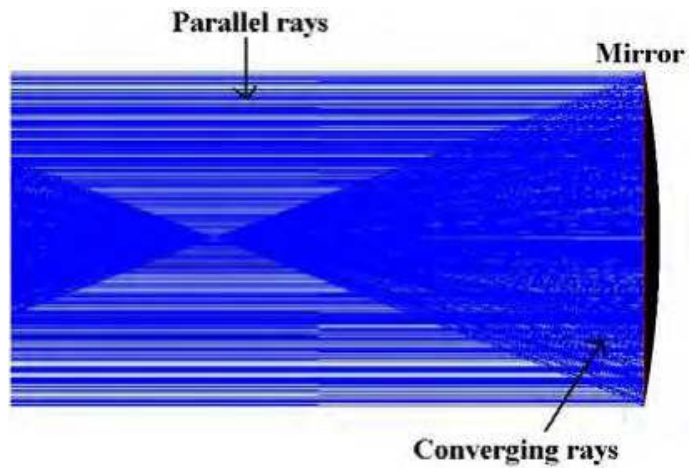

Fig. 10. Diagram of rays which arrive and are reflected by the designed mirrors.

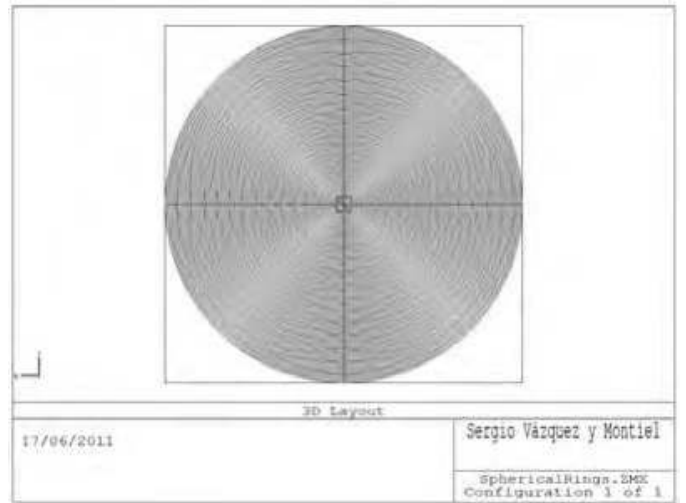

Fig. 11. Front view of the designed mirror, simulated with ZEMAX. 
The results obtained of the images generated of the point source at infinity by each mirror, and their corresponding irradiance distributions, are shown in Figs. 12 to 15. These figures show the respective results of the design using spherical, parabolic, and elliptical rings, and with conic constant calculated with GA. The image sizes shown in each one of these figures agree with those reported in Table 1 from the optimization stage.

Once the results obtained from the optimization stage have been validated with ZEMAX, the final stage in the simulation process, in which the sun is considered as object, is to replace the point source with the sun source in ZEMAX.

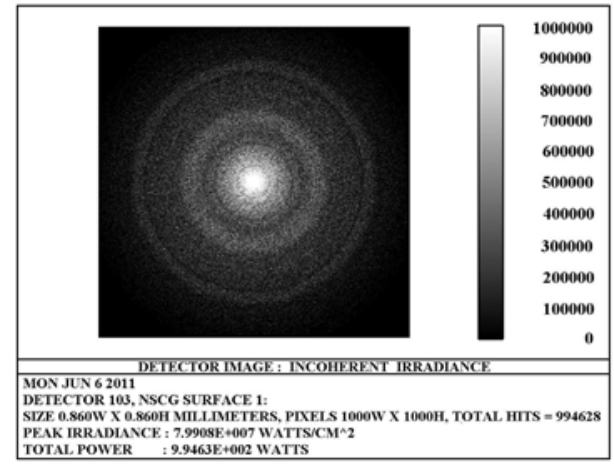

(a)

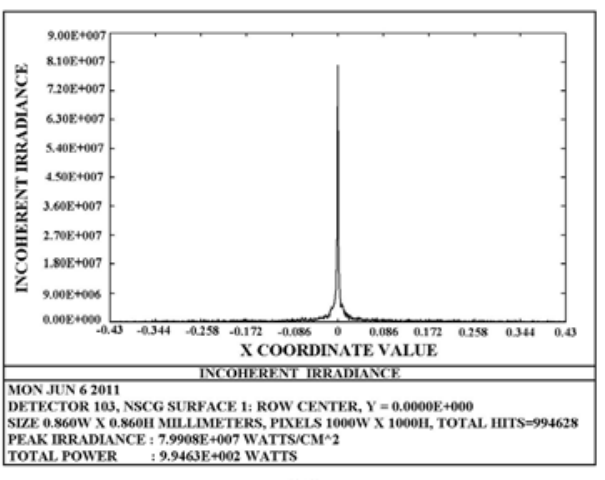

(b)

Fig. 12. a) Image of the point source, placed at infinity, generated by the mirror designed with spherical surface rings, and b) its corresponding irradiance distribution graph.

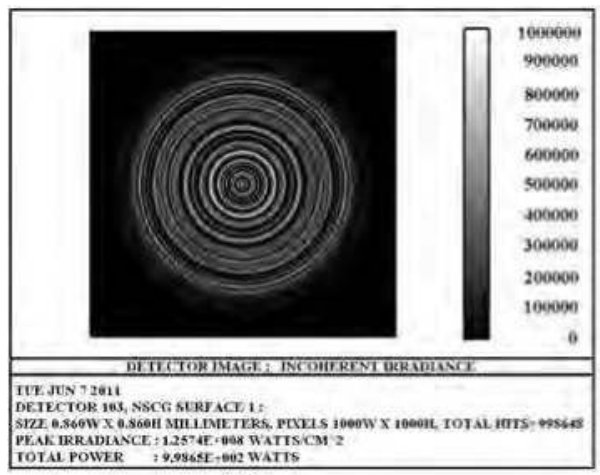

(a)

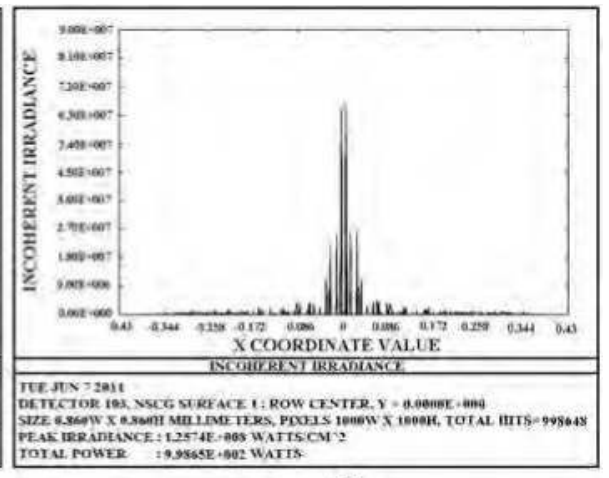

(b)

Fig. 13. a) Image of point source, placed at infinity, generated by the mirror designed with parabolic surface rings, and b) its corresponding irradiance distribution graph. 


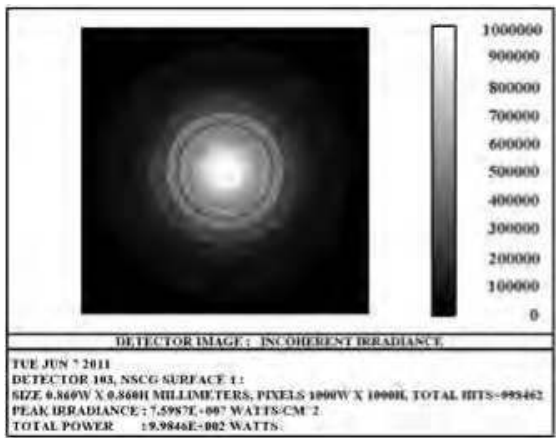

(a)

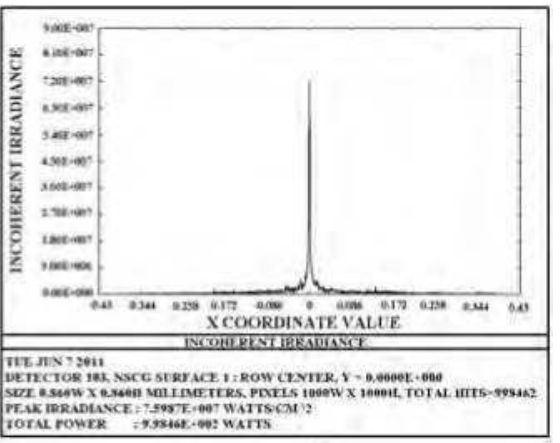

(b)

Fig. 14. a) Image of the point source placed at infinity, generated by the mirror designed from elliptical surface rings (conic constant equal to -0.5), and b) its corresponding irradiance graph.

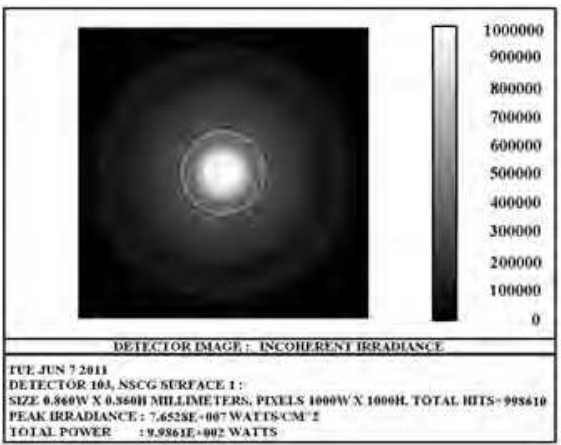

(a)

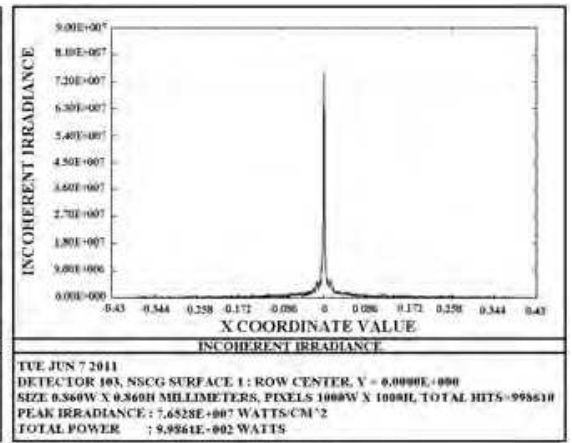

(b)

Fig. 15. a) Image of the point source, placed at infinity, generated by the mirror designed with rings having a conic constant calculated with GA equal to a -1.6279 , and b) its corresponding irradiance distribution graph.

\subsection{Simulations done using the sun source as object}

To simulate sun images generated by the designed mirrors, the sun source was generated in a DLL file by means of the following equation

$$
B(\theta)=B_{d}\left[1-(0.5051 \theta / \alpha)^{2}-(0.9499 \theta / \alpha)^{8}\right]
$$

where $B_{d}=13.639 \times 10^{6} \mathrm{~W} / \mathrm{m}^{2}$ stereorad and $\mathrm{a}=4.653 \mathrm{rad}$.

While the aureola region was adjusted by the following equation

$$
B(\theta)=B_{\alpha}(\theta / \alpha)^{-2}
$$

where $B_{\mathrm{a}}=72,200 \mathrm{~W} / \mathrm{m}^{2}$ stereorad. 
Fig. 16 shows the statement of the sun source in the ZEMAX program, while Fig. 17 shows the image of the sun before arriving at the mirror, at a distance of $150 \mathrm{~mm}$ from the vertex.

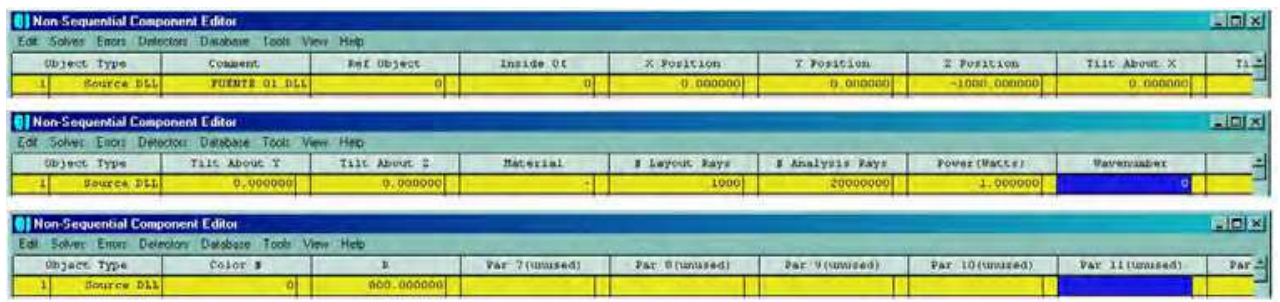

Fig. 16. Statement of the sun source in the ZEMAX program.

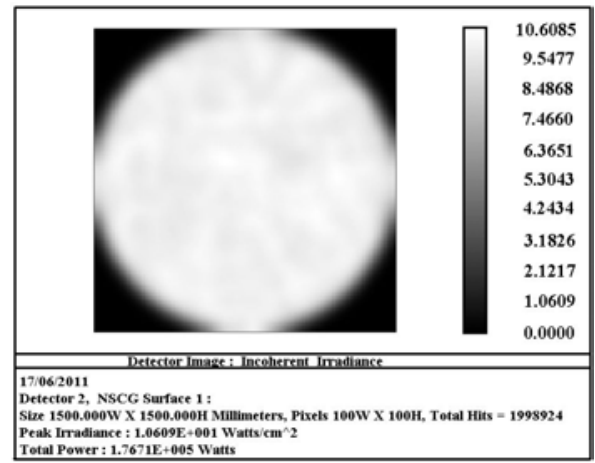

(a)

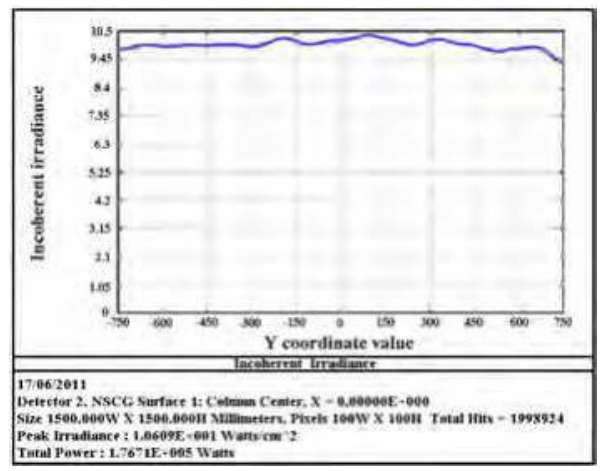

(b)

Fig. 17. a) Simulation of the sun source before arriving at the mirror, and together with b) its respective irradiance distribution.

Figs. 18 to 21 show the simulations of sun images with their respective distributions of irradiance generated with the mirrors designed with spherical, parabolic, elliptical rings, and rings with conic constant calculated with GA, respectively. Each one of these images was simulated with the ZEMAX program at a distance of $-1973 \mathrm{~mm}$. According to the FWHM criterion, the sizes of sun images generated by each mirror are shown in Table 2. 


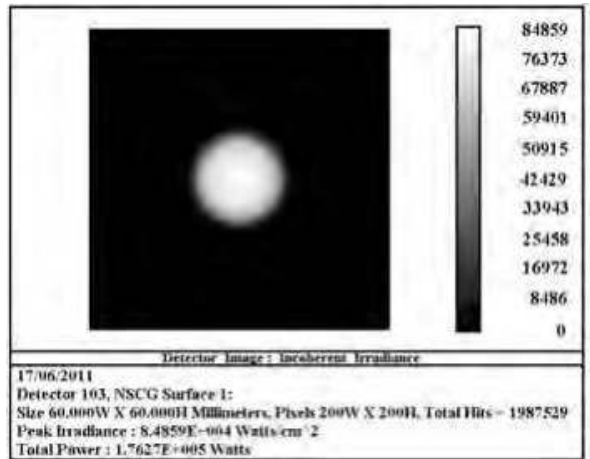

(a)

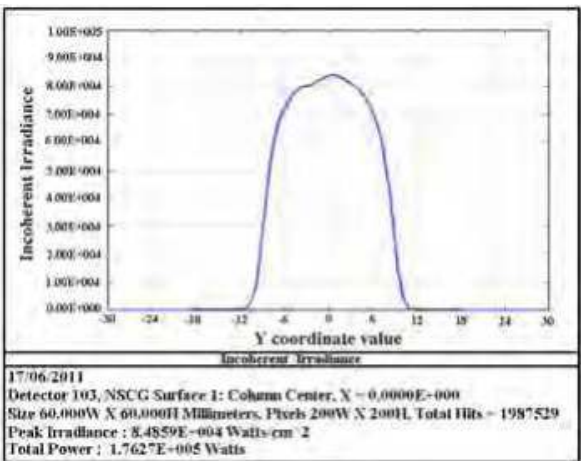

(b)

Fig. 18. a) Image of the sun source generated by the mirror designed with spherical surface rings, and $b$ ) their corresponding graph of irradiance distribution.

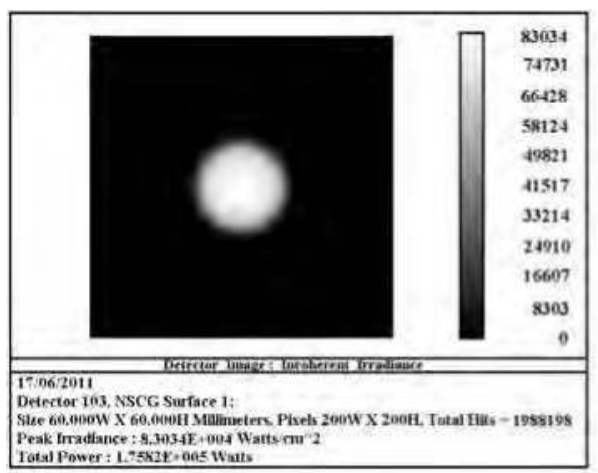

(a)

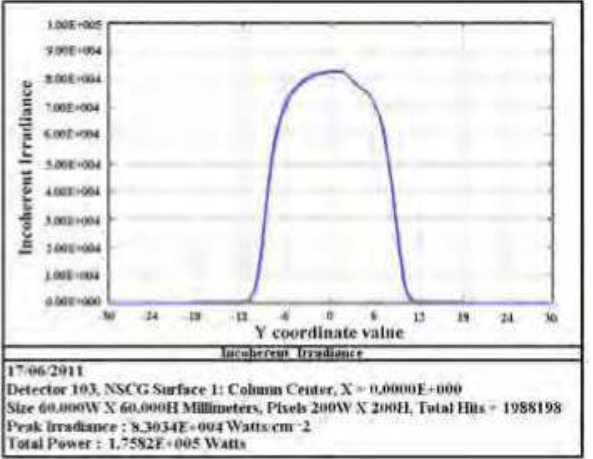

(b)

Fig. 19. a) Image of the sun source generated by the mirror designed with parabolic surface rings, and b) their corresponding graph of irradiance distribution.

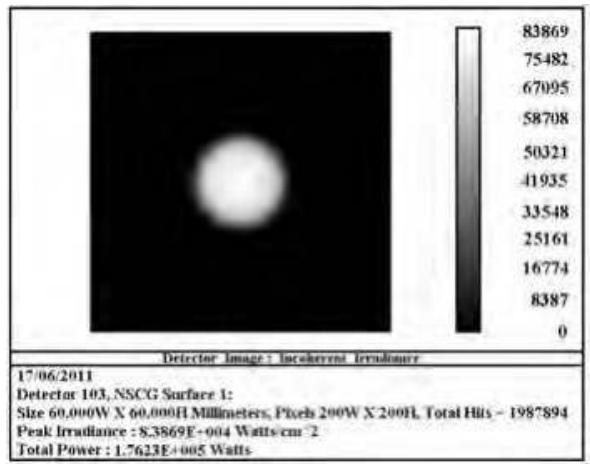

(a)

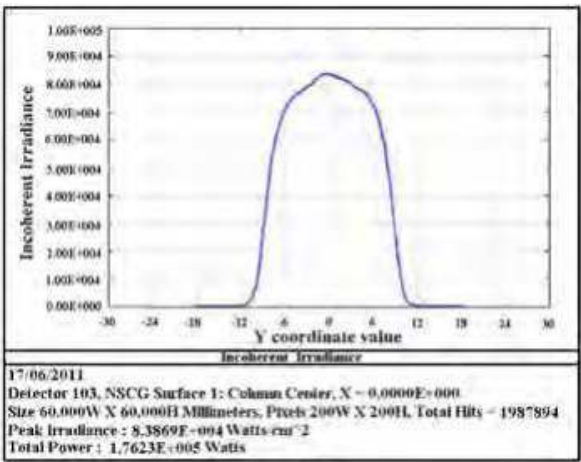

(b)

Fig. 20. a) Image of the sun source generated by the mirror designed with elliptical surface rings, with a conic constant of -0.5 and $b$ ), its corresponding graph of irradiance distribution. 


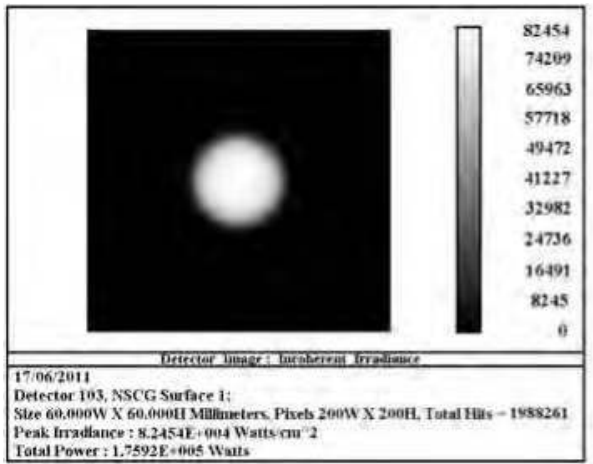

(a)

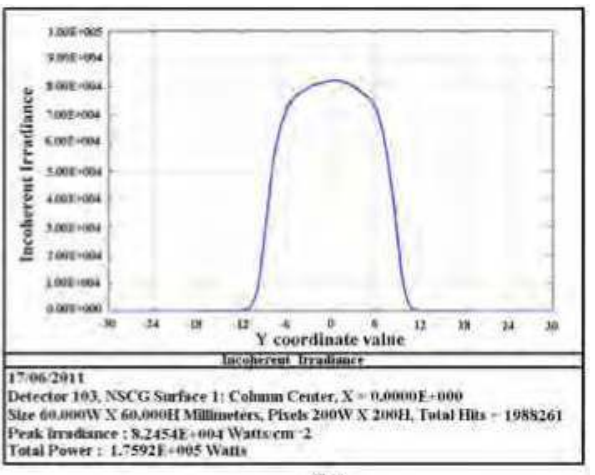

(b)

Fig. 21. a) Image of the sun source generated by the mirror designed from rings with a conic constant equal to -1.6279 calculated with GA, and b) its corresponding graph of irradiance distribution.

\begin{tabular}{|c|c|c|}
\hline Mirror designed with & Conic constant & $\begin{array}{c}\text { Size of sun image } \\
(\mathrm{mm})\end{array}$ \\
\hline Spherical rings & 0 & 16.97 \\
\hline Parabolic rings & -1 & 16.75 \\
\hline Elliptical rings & -0.5 & 16.89 \\
\hline $\begin{array}{c}\text { Rings with a conic constant } \\
\text { calculated with the GA }\end{array}$ & -1.6279 & 16.97 \\
\hline
\end{tabular}

Table 2. Results of sun image sizes generated by the designed mirrors using the FWHM criterion.

As can be seen in Table 2, the sun image sizes obtained correspond to the angular sizes obtained from the images of the point source (see Table 1), that is, the biggest angular sizes correspond to the mirrors with rings whose conic constant was 0 and -1.6279 . These very same mirrors are the ones that generate the biggest sun images, whereas the smallest images are generated with the mirror designed with elliptical surface rings with a conic constant of 0.5. Furthermore, the sun image sizes agree with the image size reported from using a mirror designed from concentric spherical rings (González-García, et al., 2009).

\section{Conclusions}

From the design of four mirrors which reduce by one order of magnitude the angular size of the image of a point source placed at infinity compared to an image generated by a spherical mirror, we could generalise the optical design method that uses the concept of concentric spherical rings for designing energy concentrators. The generalization of the method consisted in using concentric rings with conic surfaces in the optimization stage, considering two cases: 1) a constant value of the conic constant, and 2) the conic constant as one more variable to be optimized. The mirror designs could thereby remain in function of the value of the conic constant, as well as the paraxial curvature radii of the rings. The four mirrors 
designed were simulated with the commercial optic design program ZEMAX, considering the sun as object. The images of the sun were compared to the images of the point source placed at infinity, and this revealed that the sizes of the images of the sun are related to the angular sizes of the images of the point source: the mirror design which generates the smallest angular size is the mirror which generates the smallest sun image, while the mirror which generates the biggest angular size is the mirror which generates the biggest sun image.

Finally, the results obtained show that it is possible to design mirrors, solar energy concentrators, from the concept of concentric rings with conic surfaces, thereby generating an alternative method of optical design for this type of mirrors. This type of method can also be applied in the design of lens concentrators.

\section{Acknowledgment}

We wish to thank Patrick Rafferty (KFUPM University, Saudi Arabia. rpatrick@kfupm.edu.sa) for translating the original document from Spanish to English.

\section{References}

Buie, D. \& Monger, A. G. (2004). The effect of circumsolar radiation on a solar concentrating system. Sol. Energy, Vol.76, No. 3, (March 2004), pp. 181-185, ISSN 0038-092X

Cornejo-Rodríguez, A. (2007). Ronchi Test, In: Optical Shop Testing, Daniel Malacara (Ed.), 317-360, John Wiley \& Sons, Inc., ISBN 978-0-471-48404-2, New Jersey USA

Cordero-Dávila, A. \& González-García, J. (2010). Surface evaluation with Ronchi test by using Malacara formula, genetic algorithms and cubic splines. Proceedings of International Optical Design Conference (IODC), ISBN 9780819480828, Jackson Hole, WY, June 2010

Cordero-Dávila, A.; González-García, J.; Robledo-Sánchez, C. I. \& Leal-Cabrera I. (2011). Local and global surface errors evaluation using Ronchi test, without both approximation and integration. Appl. Opt., Vol.50, No.24 (August 2011), pp. 48174823, ISSN 0003-6935

Diaz-Anzures, J.; Cordero-Dávila, A.; González-García, J.; Martinez-Bravo, O.; RobledoSanchez, C.; Khrenov, B. A. \& G. K. Garipov, G. K. (2004). Low frequency Fresnel mirrors for flourescence detector telescopes. Astroparticle Phys., Vol.21, No.4, (July 2004), pp. 407-413, ISSN 0927-6505

González-García, J., Cordero-Dávila, A., Leal-Cabrera, I., Robledo-Sánchez, C.I. \& SantiagoAlvarado, A. (2006). Calculating petal tools using genetic algorithms. Appl. Opt. Vol.45, No. 24, (August 2006), pp. 6126-6136, ISNN 0003-6935

González-García, J.; Vazquez-Montiel, S.; Santiago-Alvarado, S.; Cordero-Dávila, A. \& Castro-González, G. (2009). A proposed design and fabrication of lenses and mirrors from a set of spherical rings that produce desired energy distributions for solar energy applications. Sol. Energy, Vol.83, No.12, (December 2009), pp. 22052216, ISSN 0038-092X

Leutz, R.; Suzuki A.; Akisawa, A. \& Kashiwagi T. (2000). Nonimaging Fresnel Lens concentrator-the prototype. J. Opt. A: Pure Appl. Opt., Vol.2, No.2, (March 2000), pp. 112-116, ISSN 1741- 3567 
Leal-Cabrera, I.; Cordero Dávila, A. \& Gonzalez-Garcia, J. (2009). Analytical and numerical classification of wear profiles produced with different shape oscillating tools. Opt. Eng. Vol.48, No.10, (October 2009), pp. 1-9, ISSN 0091-3286

Riveros-Rosas, D.; Herrera-Vázquez, J.; Pérez-Rábago, C. A.; Arancibia-Bulnes, C. A.; Vázquez-Montiel S.; Sánchez-González M.; Granados-Agustín F.; Jaramillo, O. A. \& Estrada, C. A. (2010). Optical design of a high radiative flux solar furnace for Mexico. Sol. Energy, Vol.84, No.5, (May 2010), pp. 792-800, ISSN 0038-092X

Santiago-Alvarado, A., González-García, J., Castañeda-Roldan, C., Cordero-Dávila, A., VeraDíaz, E. \& Robledo-Sánchez C. I. (2007). Use of linear programming to calculate dwell-times for the design of petal tools. Appl. Opt. Vol.46, No.21, (July 2007), pp. 4642-4649, ISNN 0003-6935 


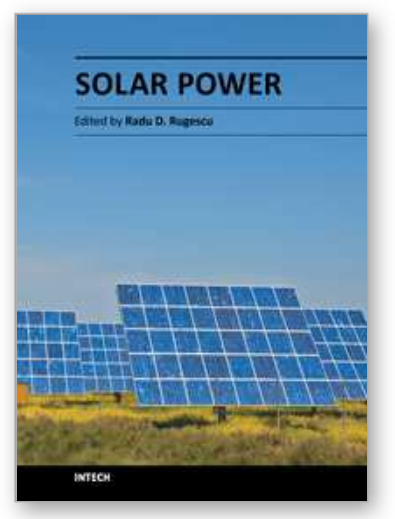

\section{Solar Power}

Edited by Prof. Radu Rugescu

ISBN 978-953-51-0014-0

Hard cover, 378 pages

Publisher InTech

Published online 15, February, 2012

Published in print edition February, 2012

A wide variety of detail regarding genuine and proprietary research from distinguished authors is presented, ranging from new means of evaluation of the local solar irradiance to the manufacturing technology of photovoltaic cells. Also included is the topic of biotechnology based on solar energy and electricity generation onboard space vehicles in an optimised manner with possible transfer to the Earth. The graphical material supports the presentation, transforming the reading into a pleasant and instructive labor for any interested specialist or student.

\section{How to reference}

In order to correctly reference this scholarly work, feel free to copy and paste the following:

Jorge González-García, Sergio Vázquez-Montiel, Agustin Santiago-Alvarado and Graciela Castro-González (2012). Concentration of Solar Energy Using Optical Systems Designed from a Set of Conical Rings, Solar Power, Prof. Radu Rugescu (Ed.), ISBN: 978-953-51-0014-0, InTech, Available from:

http://www.intechopen.com/books/solar-power/concentration-of-solar-energy-using-optical-systems-designedfrom-a-set-of-conical-rings

\section{INTECH}

open science | open minds

\section{InTech Europe}

University Campus STeP Ri Slavka Krautzeka 83/A 51000 Rijeka, Croatia Phone: +385 (51) 770447 Fax: +385 (51) 686166 www.intechopen.com

\section{InTech China}

Unit 405, Office Block, Hotel Equatorial Shanghai No.65, Yan An Road (West), Shanghai, 200040, China 中国上海市延安西路65号上海国际贵都大饭店办公楼 405 单元 Phone: +86-21-62489820

Fax: $+86-21-62489821$ 
(C) 2012 The Author(s). Licensee IntechOpen. This is an open access article distributed under the terms of the Creative Commons Attribution 3.0 License, which permits unrestricted use, distribution, and reproduction in any medium, provided the original work is properly cited. 